\title{
LOS SABERES DE LA PEDAGOGÍA
}

Héctor Lerma Jasso

\section{PRESENCIA Y ARRAIGO DE LA PEDAGOGÍA.}

LA PEDAGOGÍA, EN SU ESTATUTO ACTUAL, DEBE SER ESTUDIADA EN SUS DIVERsas facetas: como ciencia general de la educación, carrera universitaria, disciplina académica y profesión laboral. En cada una de ellas se expresan sus saberes.

En cualquiera de sus aspectos, la Pedagogía tiene, en la actualidad, una presencia cada vez más activa. Día a día crece el número de ámbitos sociales en los que se propugna una praxis educativa que, sin perder sus valores esenciales permanentes, resulte más acorde con los vertiginosos cambios que registra el mundo de hoy.

La convicción general es que sólo una inteligente síntesis entre permanencia e innovación, historia y progreso, persona y comunidad, naturaleza y cultura, dará como resultado la educación que un mundo globalizado, multicultural y plurilingüista necesita. Educación que en sus distintos niveles: instrucción, capacitación y formación, y como doble proceso de individualización y socialización sea, en sus justas proporciones, más técnicamente eficiente y más genuinamente humanista.

Esa labor de síntesis reviste mayor urgencia ahora, en cuanto que la facticidad de lo educativo se nos presenta más compleja y exigente. No es difícil constatar que, en nuestros días, a los ámbitos típicamente educativos: familia, escuela, universidad, se suman muchos otros con análogos propósitos formativos. Crece también el número de personas que sintonizan, de modo más o menos intencional y directo, con el quehacer educativo en espacios en los que, de alguna manera, se gestan los modelos de hombre, mujer, familia, sociedad, traba- 
jo, cultura..., para un nuevo milenio, más cargado de experiencias y de esperanzas. Son ambientes en los que se están forjando, teórica y prácticamente, los nuevos sistemas de educación y el futuro de la humanidad.

Esa creciente complejidad hace que los conceptos de hecho educativo, educación, mundo de lo educativo y ámbito de lo educable, se transformen y amplíen de modo inusual. Para la pedagogía, esta acelerada evolución -o revolución- resulta particularmente importante: porque la pregunta por el límite interno de lo pedagógico desemboca en un punto crucial: los límites de lo educable (Bercovich, 1994:266). Baste recordar que cuando se habla de educación integral o educación permanente, la conclusión obligada es que los límites de lo educable encierran todos los aspectos que integran el ser del hombre (hasta esa capa profunda de la personalidad llamada inconsciente, que de diversas maneras aflora y se hace presente en toda situación educacional) y se abren a todas las circunstancias de la acción humana: los límites de lo educable son también los límites del sujeto. Y serán los límites del pedagogo y su pedagogía (Idem.).

\section{EL MUNDO DE LO EDUCATIVO.}

En efecto: después de haber trascendido los contornos del hogar y excedido los límites de la escuela, el quehacer educacional, en todos sus niveles, desde los elementales hasta los altos y especializados, sobrepasa hoy las constricciones que, al menos implícitamente, le habían impuesto el aula, el campus y la estrechez de cansados sistemas reduccionistas.

Casi sin solución de continuidad, todos esos espacios humanos, habituales o emergentes, conforman en la actualidad una dilatada urdimbre en la que las cuestiones, puntos de vista, quehaceres y soluciones relativos a la problemática educativa, se remiten unos a otros de tal manera que no se pueden concebir aisladamente. Se trata de un nuevo plexo sistémico, diferen- 
ciado según los objetivos, pueblos, instituciones y épocas, al que podemos llamar el mundo de lo educativo.

Este macrosistema empírico posibilita y reclama la presencia y arraigo cada vez mayores, en lo cuantitativo y en lo cualitativo, de una renovada acción pedagógica orientada -para decirlo esquemáticamente- hacia las funciones básicas que le competen en cuanto quehacer científico: lograr una visión general y realizar una labor de síntesis de todos los saberes teóricos y técnicos acerca de la praxis educativa, y emprender acciones eficaces que aseguren su progreso.

\section{HACIA UNA SOCIEDAD DE CONOCIMIENTOS.}

Las previsiones son casi unánimes. La educación del tercer milenio habrá de ser una educación más incluyente. En los albores de un nuevo siglo, el misticismo conservadurista (manía por lo viejo; veteromanía que se opone a todo cambio) y el mesianismo revolucionario (manía por lo novedoso; neomanía que todo lo quiere cambiar) ya han mostrado su caducidad e insuficiencia. Es razonable, entonces, que la praxis educativa tienda hacia la síntesis entre tendencias aparentemente divergentes: entre el mestizaje cultural acentuado por la globalización, y la preservación de la identidad cultural de las naciones; entre la integración en la revolución tecnológica, y la protección de los valores inherentes a lo humano. Síntesis, en suma, entre historia y progreso: no hace falta ver conflicto donde sólo hay diferencia.

Esta labor de síntesis que compete a la acción pedagógica y que precisa la educación de un mundo globalizado, debe orientarse a atender la globalidad del ser de la persona y de su quehacer en el marco, también global, de la dinámica social. Este propósito exige, necesariamente, el rescate de un concepto integral de aprendizaje, apoyado en los cuatro pilares perennes de todo aprendizaje realmente formativo: aprender a conocer (lo que los antiguos llamaban theorein), aprender a hacer 
(poiesis), aprender a ser (praxis) y aprender a vivir juntos (politeia). (Delors. 1997:92-101. Lo puesto entre paréntesis es nuestro).

La aspiración es, pues, hacia un saber de lo fenoménico a la luz de lo esencial. Un saber que dé prueba de fecundidad porque conforma el obrar con el saber. Porque penetra los hechos y les asigna el lugar que les corresponde, en orden a un desarrollo humano global, personal y social, porque el ser humano no tan sólo vive, sino que, sobre todo, convive. La fuente última de la dignidad del ser humano, es su condición de persona; las relaciones interpersonales son el escenario de la existencia humana (Cfr. Yepes, 1977: 75 y 183).

En esta coyuntura, el discurso pedagógico parte del hecho de que la persona individual, como unidad de ser sustancial irreductible y actuante, sólo puede llegar a su plena realización en sociedad. Esta supone, a su vez, la acción madura, cooperante y concertada de los individuos. Antes que acción social, la educación es acción personal. El "tú" y el "nosotros", siempre son pronunciados por un yo, de cuya intimidad arranca la puesta en escena de todas sus dimensiones radicales, gracias a su constitutiva y dialógica apertura a lo social. De ahí que la fuerza de toda asociación estribe, principalmente, en su capacidad para impulsar y orientar acciones individuales concretas. (Delint. 2000:46ss).

Sólo mediante esta labor de síntesis volverá a ser eficaz la respuesta educativa a la sociedad del tercer milenio. Sociedad que, según lo demuestra la experiencia histórica reciente, no sólo tiene necesidad de máquinas sino, sobre todo, de personas capaces de dirigirlas y de resolver los graves problemas de la convivencia. De hombres y mujeres realmente educados que sepan hacer lo que no sabe hacer una máquina: decidir, juzgar, amar... y gozar de los resultados de su actuación; es decir, de todo aquello que presupone personalidad, libertad, moralidad, sensibilidad. 
Esta es, desde la actual perspectiva pedagógica, la educación que reclama la sociedad de conocimientos, según la expresión de Peter Drucker. Sociedad en la que sus miembros, dentro y fuera de la escuela -en la escuela de la vida- aprendan a aprender de modo integral y a desarrollar hábitos para seleccionar, juzgar y hacer buen uso de lo aprendido.

No sólo porque saber es poder, sino porque saber es servicio en cuanto proporciona sólidos conocimientos y principios, habilidad para manejarlos generosamente y disposición para hacer las aplicaciones justas que de ellos se derivan. $\mathrm{O}$, dicho de modo negativo: se trata de evitar, al menos, dos peligros: reemplazar, con mecanismos artificiales el profundo dinamismo de la vida; y transformar las inteligencias en manuales y repertorios de acciones y reacciones, o en colecciones de opiniones y expedientes, pero sin mayor preocupación por sus causas, razones y consecuencias (Garrigou-Lagrange. 1977:IX).

\section{UN MUNDO DE SIMETRÍAS.}

A medida que crece el mundo de lo educativo, se dilata, paralelamente, el ámbito de lo pedagógico. Esta simetría -que no es identidad- justifica que la pedagogía sea objeto de permanente actualidad, en la misma medida que la educación institucionalizada gana espacio en la vida de las personas y de los pueblos. Pero hoy, además, existen múltiples fuentes de influencia educativa, algunas de las cuales tienen tanto o más impacto que las instituciones escolar y familiar, de modo que estudiar el fenómeno educativo en la actualidad exige abarcar un conjunto amplísimo de acciones que confluyen sobre los seres humanos, sea de manera intencional o no (Sarramona y Marqués. 1985:5).

No sería razonable intentar aquí una descripción detallada del incontenible crecimiento de tales fuentes de influencia educativa. Baste señalar, a modo de ejemplo, que ante la demanda creciente de una educación más accesible y de mayor calidad, 
surgen constantemente renovados modelos de escuela y de universidad, más flexibles, menos burocratizados. Instituciones de toda índole rediseñan sus programas y tratan de adaptarlos a la especificidad de nuevos métodos y técnicas de aprendizaje y de trabajo. A una revisión crítica de los sistemas tradicionales, se establecen verdaderas redes internacionales de universidades y centros de enseñanza humanista o técnica, más en contacto con la vida y con el mundo del trabajo. Las posibilidades planteadas por internet y otras tecnologías son ya una realidad que da cabida a la didáctica satelital, a la enseñanza virtual, a los sistemas abiertos y a distancia, más versátiles y pragmáticos. Todo ello aparejado a las nuevas oportunidades del aprendizaje en-línea, del tele-trabajo y de formación a lo largo de la vida.

Se rediseñan e implementan nuevas formas y propósitos a la educación de adultos, no sólo como actividad terapéutica, sino orientada a asegurar una más digna proyección personal y más justo reconocimiento, valorización y aprovechamiento práctico de la experiencia. La educación especial sigue logrando, en el campo de la ortopedagogía, importantes realizaciones que representan un aliento y una esperanza para un número cada vez mayor de personas. Se ventilan criterios más razonables y audaces de entender la jornada laboral que, a su vez, amplían la gama de posibilidades para orientar los tiempos libres hacia una educación permanente de mayor arraigo.

En medio de esta efervescencia, la empresa, pública o privada, grande o pequeña, hace más evidente, al lado de sus intereses característicos, su vocación educativa. Esto permite que la pedagogía empresarial trascienda los viejos conceptos de capacitación laboral, y se entienda más bien como formación humana, profesional y cultural. Formación que no sólo beneficia a su personal sino que, con frecuencia, se extiende a sus familias y a la comunidad del entorno. Centros de capacitación y escuelas para empresarios, desarrollan exitosos programas para descubrir y desarrollar talentos, a fin de conformar cuadros 
operativos, administrativos, docentes y directivos de la más alta calidad profesional.

También en los campos cultural, político, recreativo, informativo, religioso, militar, asistencial..., se advierte una preocupación semejante por implementar programas de selección, capacitación, actualización y promoción de sus integrantes. Se destinan porcentajes cada vez más elevados a becas de estudio, investigación pedagógica, revisión y puesta al día de planes y estrategias educativos, así como a la creación de una estructura metodológica y tecnológica que asegure la más alta calidad pedagógica y la mayor rentabilidad en todos sentidos, según criterios económicos y académicos.

Estos, entre muchos otros factores ya presentes o que se avizoran en un futuro muy próximo, agrandan constantemente el mundo de lo educativo y reclaman, o ya aprovechan, intervenciones más decididas, comprometidas y eficaces por parte de la pedagogía.

\section{... Y DE GRAVES ASIMETRÍAS.}

Junto a tales simetrías, hemos de reconocer que en el núcleo más pragmático del mundo de lo educativo existen aún amplios sectores populares marginados y desprotegidos, numerosas piezas dispersas, investigaciones incompletas, formulaciones utópicas que ya han demostrado su caducidad e inconsistencia, mitos sostenidos por la fuerza de la rutina o por criterios reduccionistas. A modo de ejemplo, baste señalar que junto a la dramática miseria material que padecen millones de personas en el mundo, existe una no menos preocupante miseria cultural, espiritual o moral de mayores proporciones. Y en ámbitos más próximos podemos constatar que, al fantasma del analfabetismo real, se suma ahora el del analfabetismo funcional de quienes, sabiendo leer y escribir o poseyendo incluso una licenciatura, son incapaces de asimilar y hacer un uso maduro de los conocimientos adquiridos. 
Es decir: sigue habiendo, en la entraña más diferenciada de esa vasta facticidad, un nudo de problemas aparentemente disociados, pero penetrados de una interna unidad, de una misma necesidad y determinados por una finalidad común: hacer viva, comprensible y asequible la unidad de la experiencia educativa, su desarrollo, su empleo y su destino.

También estas asimetrías conforman la entraña de la problemática educativa que exige una respuesta pedagógica. Respuesta que ha de hacerse presente como una trama argumentativa y propositiva que apuesta a superar la educación existente (...). La pedagogía boceta, crea, proyecta nuevos ideales y formas de educación; al hacerlo, adquiere el compromiso, la responsabilidad de señalar el camino, de encontrar las maneras, de indicar los procedimientos para realizarlos. (Pasillas. 1994: 277).

Desde luego que son muchas las instancias responsables de desvanecer tales asimetrías. Ante tal reto, la multiplicación de agentes educativos y la consecuente diversidad de perspectivas, son dos claras justificaciones para demandar el mantenimiento de una ciencia, la Pedagogía, que permite el análisis unitario de la educación; análisis que dé sentido pleno a la acción humana estrictamente educativa, esto es, aquella acción con finalidad configuradora hacia el perfeccionamiento del sujeto y de la colectividad (Sarramona y Marqués. 1985:5).

En esta misma línea argumentativa y para ejemplificar la presencia actual y el arraigo de la pedagogía, se señala como hecho incontestable que en las dos últimas décadas, la pedagogía se ha introducido y está presente en muchos espacios profesionales inusuales de los países desarrollados. A las ramas pedagógicas ya tradicionales: Pedagogía Escolar, Pedagogía Empresarial, Pedagogía Universitaria, Pedagogía Familiar... González Simancas hace hincapié en la aparición reciente pero constante, de otras nuevas: Pedagogía Hospitalaria, Pedagogía Penitenciaria, Pedagogía Ambiental, Pedagogía Vial..., y muchas otras 
orientadas a desempeños profesionales que cuentan ya con suficientes experiencias como para suscitar una reflexión analítica en profundidad y para permitir una sistematización conceptual. (...) Lo cual significa un evento digno de ser tenido en cuenta: la aparición de una nueva rama científica marca un hito que es acicate tanto para la investigación como, a menudo, para la ampliación de la actividad profesional (en nuestro caso, la de quienes se forman como pedagogos, que así contemplan una nueva especialidad posible). (González Simancas, 1990: 9, 15).

Todo esto nos hacen ver que restringir la acción pedagógica al ámbito del quehacer escolar o señalar sólo sus insuficiencias actuales, puede resultar, al menos, un apriorismo temerario. Es verdad que la pedagogía, como toda ciencia, es una construcción humana perfectible, en constante búsqueda; es algo histórico, contingente, mutable, al menos en aquello que no depende de la naturaleza y de los fines naturales de las cosas. Siempre le es posible descubrir nuevos campos de investigación y de acción; problemas y soluciones nuevos o no contemplados antes. Sin cesar se le revelan perspectivas, investigaciones, hallazgos, incluso en ámbitos extrapedagógicos, que quizá un especialista, o un grupo, no logra desarrollar de modo cabal y satisfactorio, pero cuyo trabajo puede servir como punto de partida para que otros arriben a felices resultados.

Siempre existe la posibilidad de que la importancia de un tema pase inadvertida a los ojos de uno o varios pedagogos o que, por el contrario, se exagere el valor de determinado autor o teoría; o que una corriente o escuela pedagógica haya de reexaminar críticamente sus postulados para actualizarlos, liberarlos de prejuicios o ajustarlos a la realidad. Muchas veces es el tiempo mismo el que se encarga de echar en el olvido las obras que objetivamente carecen de valor, las cuales mueren por su propia indigencia; mientras que rescata aquellos brotes con vigoroso porvenir, pero que quizá habían permanecido 
estériles simplemente porque no se viera, en el momento, su oculta fecundidad (Quevedo. 1968:76). Ya se ve que la pedagogía, como toda ciencia, es un proyecto en permanente construcción. No hay ninguna ciencia que pueda considerarse plenamente acabada; cuando esto ha ocurrido, esa ciencia se anquilosa, se paraliza y se vuelve dogmática.

Desde la perspectiva epistemológica, es decir, en cuanto ciencia, la pedagogía es una construcción humana viva, que evoluciona, que progresa en tanto en cuanto esclarece sus elementos, delimita sus alcances, justifica sus funciones, avanza en su investigación y se libera de prejuicios. Es, primordialmente, un saber teórico, en cuanto que reflexiona científicamente acerca del ser y deber ser de la educación; y derivadamente es un saber práctico, en cuanto brota de los hechos y emprende las acciones necesarias para mejorar la praxis educativa. Se trata para decirlo técnicamente- de un saber etiológico, especulativo y experimental; descriptivo y normativo acerca del mundo de lo educativo. Por su misma naturaleza, es la ciencia encargada de concentrar y ordenar todos los saberes teóricos y prácticos acerca de la educación con el fin de analizarlos, sistematizarlos y codificarlos metódicamente.

\section{ACLARACIÓN CONCEPTUAL.}

La sucinta descripción anterior del estatuto espistemológico actual de la pedagogía, contiene algunas ideas que ameritan ciertas precisiones.

En primer lugar, conviene recordar que educación y escolaridad no son términos sinónimos. Media, entre ambos conceptos, la misma proporción que hay entre género y especie. Educación es una noción más amplia; incluye la educación que más o menos formalmente se recibe en otros ámbitos, además del escolar: familia, empresa, iglesia, sociedad, recreación... La educación no se reduce a la escolaridad.

Escolaridad es un concepto más restringido. Se refiere a una 
parte particularmente importante de la educación, pero no la agota. El término escolaridad alude sólo a la educación que se recibe en la escuela, en todas sus formas y niveles. Suele ser, por tanto, parcial, cíclica y periódica; en cambio la educación, en sentido estricto, es integral, constante y permanente, tiene cabida en todas las circunstancias de la vida e involucra todos los aspectos de la personalidad. Así se explica que la escolaridad tenga vacaciones y la educación, no. Y se explica también que Göethe haya explicado la educación como la impronta que deja en nosotros el vivir humanamente.

De modo análogo, educación y pedagogía no se identifican. La relación que hay entre ambos conceptos es la misma que hay, por ejemplo, entre la cantidad y la matemática, la materia y la física, los actos humanos y la ética, la salud y la medicina, etcétera. Es decir, la relación que hay entre una ciencia y su objeto de estudio. La educación -en el sentido amplio antes aludido- es el objeto propio de la ciencia pedagógica. De ahí que el campo de acción e investigación pedagógica no se reduzca a la escuela, ni el campo profesional del pedagogo se limite al ámbito escolar.

La educación es inherente a la naturaleza humana y es, prioritariamente, lo que se llama acción práctica. La pedagogía, en cambio, como cualquier otra ciencia, es un producto cultural y es, primordialmente, lo que se llama acción teórica.

La educación, en cuanto objeto propio de la pedagogía, suele ser aludido de distintas formas: hecho educativo, fenomenología de la educación, facticidad de la educación, el mundo de lo educativo... Como quiera que sea, la pedagogía es la teoría reflexiva de la acción y reforma de la praxis educativa (Dietrich Benner, 1998: portada). No es, sin embargo, una mera praxeología, en el sentido de limitarse a ser una reflexión sobre la praxis con propósito puramente descriptivo e informativo, sino que es, sobre todo, una teorización con propósito normativo y ejecutivo. 
El concepto de educación, hablando con propiedad, se refiere a un fenómeno que está presente a lo largo de toda la vida como proceso personal y social. Su riqueza es tal (proceso y resultado, universalidad y particularidad, proyección y constancia, esencialidad y existencialidad, integralidad y especificidad, individualización y socialización, espontaneidad y sistematicidad...) que no es posible abordarla en los límites de este artículo. A este respecto, González Simancas, con el propósitos de dar una idea, no técnica pero sí realista de su sentido más genuino y radical, señala que: La Educación está hecha de convicciones arraigadas en la inteligencia y en la voluntad, que mueven nuestra conducta en un sentido o en otro, configurando nuestra personalidad a lo largo de la vida 'a golpe de libertad', al ritmo de nuestras decisiones en el ámbito del ser y no tanto en los del hacer y los del tener, en ese largo, o breve, caminar hacia la mayor plenitud posible (González S.,1991:51).

Ya se ve que estas aspiraciones y exigencias pueden y deben ser, en definitiva, causa, contenido y consecuencia de la educación escolarizada, pero no se circunscriben a la escuela.

La escuela es, sin duda, uno de los frutos más claros de la reflexión pedagógica, pero no agota la realidad fáctica de lo educativo que es, de suyo, mucho más amplia que la realidad fáctica de lo escolar.

También la vasta riqueza de la escolaridad ameritaría un estudio aparte. Aquí me limito a decir, según los propósitos de este trabajo, que al hablar de escolaridad nos referimos a una forma específica de educación que a distintos niveles se recibe en ciertas instituciones sociales, públicas o privadas, cuya razón de ser es precisamente la educación formal sistematizada.

La escuela educa sin agotar ni enclaustrar la educación. En este sentido, la comunidad escolar es abierta, tiene circulación permanente hacia adentro y hacia afuera. Se renueva constantemente por el flujo periódico de alumnos y profesores. Es, en más de un sentido, extensión del hogar y reproducción de la 
vida social. De ahí que los aires de la escuela dependan en gran parte de los vientos que corren en la sociedad. (Ibáñez-Martín. 1989:10)

La misión de la escuela es brindar una enseñanza educativa, en la que, sobre la base de una libertad discretamente regulada y un trabajo académico razonablemente sistematizado, se establece una relación intersubjetiva que motiva al alumno para que, mediante su personal esfuerzo y el trabajo grupal, realice el aprendizaje, cultive los valores, desarrolle habilidades y fomente en sí mismo hábitos de iniciativa, espontaneidad, colaboración y servicio.

\section{EDUCACIÓN Y PEDAGOGÍA.}

La relación y distinción entre educación y pedagogía ya estaban muy claras en Herbart cuando en su obra, "Pedagogía general derivada del fin de la educación", al argumentar acerca del rango científico de la pedagogía, la definió como "la ciencia preparatoria de la práctica educativa", distinguiendo, sin escindir, la teoría pedagógica de la práctica educativa: "nuestra esfera -afirma- es la ciencia" (Herbart. 1806).

También en "Educación y sociología" de Durkheim aparece más que tácita la misma diferenciación al decir, a propósito de la "Naturaleza y métodos de la pedagogía": "Que las cosas de la educación pueden ser objeto de una disciplina que presente todos los caracteres del proceder científico, es algo fácil de demostrar. En efecto, para que pueda llamarse ciencia a un conjunto de estudios, se necesita, y es suficiente, que éstos presenten los caracteres siguientes: 1) que versen sobre hechos reales (en nuestro caso, la facticidad de lo educativo) ofrecidos directa o indirectamente a la observación metódica... Una ciencia se define por su asunto; supone, por consiguiente que este asunto (la educación, el hecho educativo) existe, que se le puede indicar con el dedo, de algún modo señalando el sitio que ocupa en el conjunto de la realidad. 2) que estos hechos presenten 
entre sí la suficiente homogeneidad para que se les pueda clasificar en una misma categoría (lo educativo)". (Cfr. Durkheim. 1986:88. Lo puesto entre paréntesis es nuestro).

Es así como, según Durkheim, el hecho educativo es estudiado por la pedagogía para conocerlo en el doble sentido del conocimiento científico: conocimiento teórico (epistéme) con derivación hacia el conocimiento práctico (techné). Y después de aplicar tales principios a la pedagogía, concluye que "no hay razón para que la educación no venga a ser objeto de una investigación que satisfaga todas estas condiciones y que, por consecuencia, presente todos los caracteres de una ciencia" (Idem).

La clave para acceder al estatuto científico de la pedagogía es la pregunta: ¿puede, la educación, ser estudiada científicamente? Si la respuesta es no, no hay pedagogía posible. Si la respuesta es sí, la pedagogía queda justificada como ciencia independiente y autónoma, al menos con la independencia y autonomía relativas que cualquier otra ciencia particular puede tener en el mundo científico actual que se caracteriza, primordialmente, por su interdisciplinariedad.

Como toda ciencia, la pedagogía se caracteriza por su objeto de estudio. Técnicamente se dice que el objeto material propio de la pedagogía es el hecho educativo (expresado, repito, como: la educación, el mundo de lo educativo, la facticidad educativa, la fenomenología de la educación...). El objeto formal, o punto de vista desde el cual realiza su estudio, es la cientificidad del hecho educativo.

Históricamente el hecho educativo es anterior a toda teoría pedagógica. Primero se educa, después se teoriza sobre la educación. Bien dice Lemus que "sin educación no habría pedagogía; pero sin pedagogía, la educación carecería de significación científica" (Lemus. 1991:31). 


\section{EL CORPUS PEDAGÓGICO.}

Como objeto de estudio, la educación constituye una fenomenología compleja que requiere una comprensión sintética, propia de métodos científicos distintos (Yepes. 1996: 47).

En este sentido, la pedagogía, como estudio intencionado, sistemático y científico de la educación (Lemus, 1991: 30), se encarga de detectar, concentrar y unificar -que no es lo mismo que uniformar- todos los saberes teóricos y prácticos acerca de lo educativo para constituir el corpus pedagógico.

Este corpus científico acerca de la educación es necesariamente complejo y, por lo mismo, permite la concurrencia multidisciplinar. Esto se explica por la imposibilidad lógica de aislar totalmente los fenómenos que están unidos en la realidad. De ahí que la indagatoria pedagógica siempre haya surgido mezclada con propósitos e intereses antropológicos, éticos, políticos, psicológicos, sociológicos, económicos, etcétera.

Se considera también que, de no integrarse ese corpus acerca de lo educativo, muchas intuiciones individuales -a veces geniales-, sistemas parciales ya probados con éxito, teorías particulares con evidentes valores propios, experiencias de procedimientos eficaces, etcétera, correrían el riesgo de frustrar gran parte de su fecundidad al quedar aislados y segregados del tratamiento científico, y al no poder universalizar y hacer trascender sistematizadamente sus conclusiones. $\mathrm{O}$, por el contrario, se correría el riesgo de repetir experiencias que ya han demostrado su improcedencia.

Existe también una gran cantidad de originales y audaces realizaciones en materia educativa que proceden de ambientes extrapedagógicos que, de hecho, es analizada críticamente y sumada, según los resultados de la crítica, al cuerpo de saberes teórico-prácticos de la pedagogía.

Todo esto subraya la complejidad de la fenomenología de la educación, del corpus pedagógico, su discurso y su método. 
Porque la complejidad de una ciencia le viene de la complejidad de su objeto. No resulta extraño, entonces, que también la pedagogía haya sido interpretada desde claves muy diversas. Sin pretender una relación exhaustiva, podemos ejemplificar: clave idealista (Kant, Hegel, Fichte, Schiller...), neo-idealista (Gentile, Lombardo-Radice, Ferreti...), sociológica (Comte, Natorp, Durkheim, Marx, Barreda...), evolucionista (Huxley, Spencer, Bain...), existencialista (Kiekergaard, Jaspers...), psicológica (Binet, James, Claparède, Piaget...)... En fin, la pedagogía ha sido leída también desde las ciencias de la cultura (Dilthey, Spranger), desde la teoría del valor (Windelband, Rickert), desde las teorías de la conciencia histórica (Dilthey); desde las teorías estatistas (Napoléon, Rousseau...), etc.

Por fortuna, ya ha quedado suficientemente demostrado que también es posible interpretar el discurso pedagógico desde la pedagogía misma. En su estatuto actual, se puede leer la pedagogía en clave pedagógica.

\section{EL HECHO EDUCATIVO Y LA ACCIÓN PEDAGÓGICA.}

Lo anterior significa que la complejidad de la facticidad de la educación como objeto de estudio, no la condena a la dispersión, ni confunde el hecho educativo con otros (social, psíquico, laboral, político, cultural, económico...). La acción pedagógica, por la índole de su objeto, de sus funciones, de su orientación de fondo, de su modo de construirse y de expresarse, tiende a poner de relieve la particularidad del hecho educativo y salvaguardar su integridad: como hecho humano (integridad de la formación de la personalidad como principio de actividad) y como hecho social (integridad de la sintalidad social, como fuerza aglutinante en el escenario de la actuación solidaria, autónoma y responsable de las personas).

La unidad, homogeneidad e integridad específica del hecho educativo como materia de estudio de la acción pedagógica, fue señalada por Durkheim al decir que si los hechos fueran 
irreductibles los unos frente a los otros, habría no una ciencia, sino tantas ciencias diferentes como especies distintas de cosas que estudiar (Idem).

La integridad del hecho educativo a veces se ha perdido por falta de concreción científica. Tal concreción no ha sido posible mediante una mera yuxtaposición de puntos de vista parciales, sin cohesión gnoseológica. Esa cohesión le compete a la acción pedagógica. El hecho educativo no es un pastel que pueda quedar repartido entre muchas ciencias, aunque todas puedan y deban participar en el entendido de que, saber algo es conocerlo del modo más perfecto: unitario, completo y en todos sus niveles: técnico, científico, filosófico y teológico. A esto aspira la acción pedagógica con el apoyo de las demás ciencias. En esto reside su autonomía y la originalidad de sus materiales, intereses y funciones.

Por otra parte, no hay, en el panorama científico moderno, ninguna ciencia, absolutamente eleutérica (independencia de las demás ciencias), autónoma (regida sólo por sus propias leyes) y autártica (sostenida sólo por sus propios recursos): la matemática necesita de la lógica; la lógica de la linguística; la metafísica de la física. La química no se demerita al apelar a la matemática. No es injurioso para la psicología recurrir a la anatomía, fisiología, sociología, antropología, etc. La sociología no se afrenta al apelar a la ética, psicología, política, pedagogía, economía... (Este es un problema muy añejo: el del sistema, jerarquización y relación entre las ciencias; problema que ya los antiguos supieron resolver mostrando que la relación entre las ciencias no debe ser anárquica, ni despótica, sino política -en el buen sentido del término-).

La relación de la pedagogía con la filosofía, como la más general, la más radicalmente etiológica y la máximamente orientadora de las ciencias, requiere un estudio aparte. Lo que está claro es que todas las ciencias, tanto las de la naturaleza como las humanísticas, forman un plexo en el que unas se 
conectan con otras. El mito de la ciencia pura, autosuficiente e incontaminada se deshizo hace mucho tiempo. (Ver, por ejemplo, "Más brillante que mil soles". Robert Jungk. Ed. Argos. Barcelona,1976).

Cada ciencia contempla un aspecto de la realidad física o humana, según el caso y en razón de la limitación que cada una ha de imponer al área de sus estudios. Esto exige, naturalmente, no sólo la no invasión de campos (objeto material), sino la no confusión de perspectivas (objeto formal). Y exige, más que concordancia e interdisciplinariedad, la conciliación gnoseológica (metafísica del conocimiento).

En efecto: el hecho educativo es estudiado por muchas ciencias. Pero, fuera de la pedagogía, las demás (biología, psicología, sociología, filosofía, economía, política, historia...) la estudian no como objeto propio y directo, sino de modo indirecto y tangencial. Por eso sus conclusiones son, necesariamente, valiosas pero parciales (de no ser así, cabría el absurdo de que todas las demás ciencias se redujeran a pedagogía o que la pedagogía se fraccionara entre ellas). La única que asume el hecho educativo como objeto propio para garantizar su concreción y sustento gnoseológico, en sus aspecto especulativo y técnico (y hasta ahora no se ve qué impedimento pueda haber en ello), es la pedagogía.

Lo que procede, entonces, es determinar, a la pedagogía y a las demás ciencias que inciden sobre el hecho educativo, la medida justa y el modo específico de su confluencia en ese estudio. El hecho educativo, como cualquier hecho humano (psíquico, social, político, económico.., excede la simple multidisciplinariedad. Por ello se señala, como función preliminar de la pedagogía en su estatuto actual, decantar el hecho educativo de adherencias ilegítimas, de ideologías reduccionistas, de injerencias sectaristas..., para, simultáneamente consolidar la construcción y reconstrucción del corpus propiamente pedagógico cuyas verdades intrínsecas aseguren su funcionalidad. 
(En otro escrito -"Pedagogía: su estatuto actual"- hemos analizado el hecho de que, hablar de "Ciencias de la educación", es referirse a la forma que algunas universidades han elegido de estructurar los planes de estudios sobre la educación. Es, pues, atender a un criterio curricular, no epistemológico).

\section{LO QUE DEBE EVITAR LA PEDAGOGÍA.}

En este punto, y con propósito de dejar clara nuestra posición, es necesario hacer algunas precisiones.

Al subrayar el estatuto científico de la pedagogía, no pretendemos ubicarnos en los terrenos del cientismo positivista -que es el "romanticismo de la ciencia"-, fruto de la ingenua creencia de que no existen límites para la validez, extensión y poder del conocimiento científico, sustentado sólo en "hechos" y en leyes de exactitud matemática. Desde luego que hay una relación muy estrecha entre matemática y pedagogía. Aquélla es útil porque ofrece un aparato deductivo -conveniente y convencional- para la predicción y la generalización. Lo que la pedagogía debe evitar es caer en la actitud extrema que conduce a una noción de educación como "ingeniería de la conducta", entendida en términos de input y output, cuyo resultado óptimo es la automatización del sujeto educando. (Cfr. Marx y Hillix. 1978:368-387s).

En este sentido, la pedagogía no es lo que se llama una ciencia exacta. Esto no le resta dignidad, sino todo lo contrario. Al versar sobre la educación del hombre y, por el hombre, de la familia, la cultura, las instituciones sociales y los pueblos, se ubica entre las ciencias llamadas humanidades, "desde el momento en que la dignidad del hombre radica fundamentalmente en la libertad (y ésta es el motor de la educación y de la democracia), es lógico que las humanidades sean por antonomasia todos aquellos conocimientos en los que haya una especial patencia de la libertad" (Ibáñez-Martín. 1989:87). Las ciencias humanísticas versan sobre personas; las ciencias técnicas 
versan sobre cosas. Los objetos son dóciles, los sujetos son problemáticos.

Como ciencia humanista, la pedagogía se interesa por los fines de la vida humana, no sólo por los medios. No desprecia los medios, pero no olvida los fines. Las ciencias técnicas, al trabajar con cosas, no hablan de los fines del hombre, por eso suelen ser indiferentes a los valores humanos. Están dispuestas a decirnos cómo conseguir un determinado fin, pero, primero, ese fin debe darse. El triste dilema del científico de hoy es constatar que su ciencia puede igualmente dirigirse al bien o al mal. Su orientación debe venir de otro sitio.

Tampoco propugnamos cierto tipo de ciencia -o, más bien, pseudociencia, o ideología en el sentido reprobable del término- que, afectada por una especie de complejo que la hace sentir como prima segunda o pariente pobre y lejana de la familia científica, en un intento desesperado por ponerse un disfraz de respetabilidad y verosimilitud, se autoconstruye sobre tecniquerías -para usar una palabra de Borges- que aparecen unas veces con ropaje científico y otras, atacando a la verdadera ciencia e incluso a la razón. Para Garrigou Langrage, "es un hecho, en la hora actual, que el sabio moderno rinde un culto escrupuloso al método científico, en tal forma que parece más interesado por el método que por la verdad misma a que todo método debe conducir" (Garrigou-Lagrange. 1977: 18).

Esto es importante porque, según las exigencias epistemológicas, una ciencia se caracteriza por su objeto antes que por su originalidad, autosuficiencia o método; por ser un conocimiento de la realidad (entes, sucesos, procesos) antes que por sus aspectos lógicos y metodológicos, que sólo tienen sentido si efectivamente sirven para el conocimiento de la verdad. Un conocimiento falso o erróneo no es científico, por muchos razonamientos originales, autónomos y metodológicamente bien trabados que pueda contener. "La concatenación de las ideas no verdaderas, y su transmisión a los 
demás y a otras generaciones hace posible el progreso sistemático del error, de un modo lógico e histórico, envuelto no ya en la apariencia de una simple frase, sino de un cuerpo científico" (Cfr. Sanguineti. 1977:19).

No es que el quehacer pedagógico deba carecer de actitud y proceder científicos, o de un lenguaje y recursos técnicos específicos. Lo que decimos es que, mientras la pedagogía quiera conservar la sensatez, el sentido común y cumplir eficazmente su misión, ha de evitar caer en ciertos excesos. Excesos que, en vez de facilitar la comprensión de la naturaleza de la educación y la realización de una acción educativa a la medida del hombre y de la sociedad, terminan -según lo demuestra la historia de las dos últimas centurias- por convertir las ciencias humanísticas en instrumentos de dominio sobre los humanos como armas al servicio del poder. "Nosotros -para decirlo con Bergson- sólo le pedimos a la ciencia que siga siendo científica" (Cfr. Ibáñez-Martín. 1989: 76).

\section{LOS SABERES DE LA PEDAGOGÍA}

La pedagogía es una empresa multifacética que, como hemos visto, puede ser explicada de diversas maneras. Algunas ponen el acento en un modo de pensamiento -la actitud especulativa o teórica- como la característica principal. En otras, es primordialmente un tipo de praxis o técnica; se considera que el método científico-experimental es el rasgo más importante. Otras destacan el producto de una combinatoria metodológica -el corpus de conocimientos sistemáticamente ordenados, su coherencia interna y su funcionalidad pragmática-. Parece ser que la explicación más segura es la que acepta todos esos elementos y considera la pedagogía como empresa integral: hombres que piensan con una cierta actitud, que utilizan métodos científicos para indagar sobre las causas del fenómeno educativo, para producir teorías que constituyen descripciones ordenadas y explicaciones del mundo de lo educativo, y proponen e 
implementan acciones para mejorar la praxis educativa. (Cfr. Marx y Hillix. 1978:15).

De esta forma, los saberes de la pedagogía son, fundamentalmente, una manera de ordenar, de dar unidad y hacer inteligible la problemática de la educación y de las circunstancias de la praxis educativa, a fin de garantizar, hasta donde sea posible, las mejores condiciones técnicas y éticas para su realización. Así resulta razonable exigir a la pedagogía, como a cualquier otra ciencia, la satisfacción de las tres notas fundamentales del saber científico:

1) en cuanto a su orden interno:

* coherencia (compatibilidad real de todos los componentes y todos los funcionamientos parciales);

* estabilidad (mantenimiento de su configuración y su modo de funcionamiento a pesar de las perturbaciones -interiores o exteriores- que pueden producirse); y

* optimalidad (adaptación lo más estrecha posible entre los efectos buscados y los recursos puestos en funcionamiento);

2) en cuanto a la posibilidad de situarse en relación con otras ciencias, pues para experimentar aislamos artificialmente, pero la vida no se agota en el círculo cerrado de un sistema;

3 ) en cuanto a su posibilidad de transformación, de modo que la estabilidad de que hablamos sea una condición que permita el progreso, pero este progreso debe darse en la medida en que nuevos acontecimientos hagan posible inducir la necesidad de poner en tela de juicio alguno o todos los principios en que se apoye la ciencia. (Cfr. Ibáñez-Martín. 1989:85s).

Este proceder científico de la pedagogía ha de realizarse en el marco de una filosofía abierta, clara y firme, y conectada con los demás rayos de la cultura. Esto impone a la acción pedagógica unas directrices definidas. Ha de ser una acción interdisciplinar y, por ello, programada y metódica. Esto es imprescindible para que la pedagogía mantenga el carácter de trabajo sistematizado, realizado dentro de la vasta y poliédrica 
organización científica que, poco a poco va superando la idea de que la metodología sólo es válida si sirve para el logro de resultados técnicos y útiles. La experiencia reciente demuestra que si bien, gracias a la técnica, la capacidad pragmática del hombre ha adquirido una amplitud insospechada, también ha dilatado cada vez más las zonas en las que la ciencia y la técnica se confunden, hasta el punto de que ambas han llegado a constituir un conjunto unitario.

Esta confusión nos obliga a no dejar a la pedagogía en un terreno ambiguo como disciplina teórico-práctica. A este respecto, son varias los aspectos de la pedagogía que conviene destacar con el fin de esclarecer su estatuto epistemológico y desechar los prejuicios de que la pedagogía sea una pura especulación acerca de la educación (acción teórica, filosofía aplicada), o mera tecnología didáctica (acción práctica, técnica de la enseñanza).

Podemos subrayar, entonces, del ser y quehacer de la pedagogía y tratando de compendiar lo que llevamos dicho, su condición como:

a) saber teórico, es decir, como ciencia (epistéme, scientia=saber con certeza etiológica, con la seguridad que se consigue sistemáticamente, mediante el recurso a métodos especulativos y empíricos orientados a la búsqueda rigurosa y al entendimiento -logos- de las causas y principios del fenómeno educativo, que es tanto como establecer las demostraciones en las que se apoya);

b) ciencia de raigambre humanista, en cuanto que se plantea la problemática de esa realidad específicamente humana que llamamos educación, en sus fundamentos y fines, en su universalidad y proyección, en su teoría y práctica;

c) saber práctico (praxis: aplicación de las conclusiones de la teorización a la realidad fáctica para transformarla y mejorarla). Es así un saber hacer técnico que desarrolla el hábito de realizar el trabajo pedagógico con habilidad e ingenio y para obtener 
resultados ventajosos en la solución de los problemas con la obtención y producción de algo útil;

d) contenido cultural que, al convertirse en materia de enseñanza y aprendizaje -en nuestro caso como carrera universitaria a nivel de licenciatura, maestría y doctorado- es entendido como disciplina académica. Sólo en sentido académico derivado, la pedagogía es una disciplina. Como tal, deriva hacia una aplicación práxica inmediata en tanto en cuanto es vivenciada por el estudiante, futuro profesional, como un saber prudencial, es decir, como el mejor conocimiento de las cosas humanas, personales y sociales, y del mejor modo de conducirlas;

e) saber prudencial como elemento articulante entre el saber teórico y el saber técnico que, en la práctica, son separables. Por eso hay personas que saben teóricamente muy bien las cosas, pero son incapaces de llevarlas a la práctica; o, a la inversa, personas que técnicamente son hasta geniales, pero no saben qué orientación dar a su genialidad. Desde este punto de vista, el saber prudencial es la acción o el conjunto de acciones del saber teórico que tiene, como primer resultado práctico, la autoformación del propio hombre prudente, es decir del educando (del discípulo que adquiere la disciplina pedagógica), del profesional y de todo cultivador de la ciencia pedagógica. El saber prudencial se puede explicar de muchas maneras. Brevemente diremos que consiste en saber aplicar las conclusiones del saber teórico a la concreta realidad en la que nos encontramos; es saber acertar sobre lo que conviene hacer y sobre el mejor modo de hacerlo; y es, también, el hábito intelectual por medio del cual sabemos lo que es honesto o no;

f) saber prudencial que, por referirse al conocimiento de los fines y la elección de los medios idóneos para alcanzarlos, posee, además, una aplicación práxica mediata a través de la educación, entendida ésta como la acción práctica dirigida a la formación de otros. Por eso el saber prudencial es un saber peda- 
gógico. Y es, también, un saber directivo, bajo cuya dirección se usan rectamente (ortopraxis) la competencia profesional y los medios técnico-científicos de acuerdo a determinados objetivos.

g) Este saber integral capacita para el desempeño de la pedagogía como profesión laboral, en la medida en que proporciona -debe proporcionar- la competencia y versatilidad necesarias para desempeñar, con eficiencia personal e institucional, la función pedagógica en diferentes contextos, o diversas funciones en el mismo contexto, y con base en los requerimientos de calidad necesarios para la realización de la obra profesional bien hecha. Esta competencia habrá de manifestarse como: aptitud científica, competencia técnica, habilidad gerencial, compromiso social, conciencia profesional, ética profesional, espíritu de servicio y deseo práctico eficaz de crecimiento profesional.

De este modo los saberes de la pedagogía, conforman un corpus científico que, como disciplina académica y carrera universitaria, puede habilitar para el desempeño competente y prudente de una profesión. "La idea de que el progreso técnico reduce la necesidad de la prudencia -afirma Millán Puelles- supone un craso desconocimiento de la esencial distinción entre ser competente y ser prudente. Bien lejos de aminorar la necesidad de la prudencia, las conquistas de la técnica dilatan el campo de aplicación de esta virtud (prudencia). La mayor abundancia y perfección de los productos del ingenio humano (técnica) son moralmente neutras, y no aseguran, de ninguna forma, la honestidad de su uso" (Millán Puelles. 1984:499).

\section{BIBLIOGRAFÍA}

1. Benner, Dietrich. La Pedagogía como ciencia. Pomares-Corredor. Barcelona, 1998.

2. Bercovich, Susana. Los límites de la pedagogía. En: La pedagogía hoy. UNAM. México, 1994. 
3. Bernstein, B. La estructura del discurso pedagógico. Morata. Madrid, 1997.

4. Brugger, Walter. Diccionario de filosofía. Herder. Barcelona, 1988.

5. De Alba, Alicia. ¿Teoría pedagógica? UNAM. México, 1992.

6. Delint, Alfonso. Estudio sobre la historia y el progreso en L. von Mises. (Tesis: Universidad Panamericana). México, 2000.

7. Durkheim, Émile. Naturaleza y método de la pedagogía.En: ¿Teoría pedagógica? O.C.

8. Fermoso, Paciano. Teoría de la educación. Trillas. México, 1994.

9. Galino, María A. Historia de la educación. Gredos. Madrid, 1988.

10. Garrigou Lagrange, R. Las tres etapas de la vida interior. Palabra. Madrid, 1977.

11. Gilbert, Roger. Las ideas actuales en pedagogía. Grijalbo. México, 1977.

12. González-Simancas, J. L. Pedagogía Hospitalaria. Narcea. Madrid, 1990.

13. Gore, J. M. Controversias entre las pedagogías. Morata. Madrid, 1996.

14. Gramsci, Antonio. La alternativa pedagógica. Fontamara. México 1998.

15. Gutiérrez, Isabel. Historia de la educación. Nercea. Madrid, 1972.

16. Ibáñez-Martín, José A. Hacia una formación humanística. Herder. Barcelona, 1989.

17. Jungk, Robert. Más brillante que mil soles. Argos. Barcelona, 1976.

18. Lemus, Arturo. Pedagogía: temas fundamentales. Paidós. Buenos Aires, 1969.

19. Leperlier, Guy. La comunicación pedagógica. Ed.Mensajero. Bilbao, s/d.

20. Lerma J., Héctor. Pedagogía: su estatuto actual. Nota técnica. Universidad Panamericana. México, 1999.

21. Marx, M. Y Hillix, W. Sistemas y teorías psicológicas contemporáneos. Piados. Buenos Aires, 1978.

22. Millán-Puelles, Antonio. Léxico filosófico. Rialp. Madrid, 1984.

23. Pasillas, M.A. y Furlán, A. Dos miradas a la pedagogía como intervención. Apud: La pedagogía hoy. UNAM. México, 1992.

24. Pérez López, J. A. Liderazgo. IESE. Barcelona, 1996.

25. Quevedo H. P. La filosofía de la educación como ciencia. (Tesis: Istituto Internazionale di Scienze dell'educazione). Roma, 1968.

26. Sanguineti, Juan José. La filosofía de la ciencia. EUNSA. Pamplona, 1977.

27. Sanguineti, Juan José. Ciencia y modernidad. C. Laholé. Buenos Aires, 1988.

28. Urdanoz, Teófilo. Historia de la filosofía. BAC. Madrid, 1988.

29. Sarramona y Marqués. ¿Qué es la Pedagogía? CEAC. Barcelona, 1985.

30. Yepes, Ricardo. Fundamentos de antropología. EUNSA. Pamplona, 1997. 